\title{
Prospects of Cage Fish Farming in South Western Uganda
}

\author{
Gerald Kwikiriza $^{1,}$, , Tony Mwesigwa ${ }^{1}$, Alex Barekye ${ }^{1}$, Ivan Abaho², Ambrose Rwaheru Aheisibwe ${ }^{3}$, \\ Rose Mwesige $^{1}$
}

${ }^{1}$ Kachwekano Zonal Agricultural Research and Development Institute, Kabale, Uganda

${ }^{2}$ Bulindi Zonal Agricultural Research and Development Institute, Hoima, Uganda

${ }^{3}$ Department of Economics, University of Dar es Salaam, Dar es Salaam, Tanzania

\section{Email address:}

gkwikiriza2@gmail.com (G. Kwikiriza)

${ }^{*}$ Corresponding author

\section{To cite this article:}

Gerald Kwikiriza, Tony Mwesigwa, Alex Barekye, Ivan Abaho, Ambrose Rwaheru Aheisibwe, Rose Mwesige. Prospects of Cage Fish Farming in South Western Uganda. Agriculture, Forestry and Fisheries. Vol. 7, No. 2, 2018, pp. 52-57. doi: 10.11648/j.aff.20180702.12

Received: March 15, 2018; Accepted: April 27, 2018; Published: June 25, 2018

\begin{abstract}
The study was conducted to identify the constraints and potential opportunities of cage fish farming in South Western Highland Agro-Ecological Zone (SWHAEZ). 82 questionnaires were administered to six respondent groups (current cage fish farmers, potential adopters of cage aquaculture, farmers who have abandoned cage aquaculture, regional and district fisheries officers, and financial institutions) to obtain insight into the challenges in cage fish farming as well as opportunities that can be exploited to promote cage fish farming. People in relevant government institutions were also interviewed. Primary results show that lack of funds and lack of government extension services are key challenges in cage fish farming. Lack of funds incapacitates farmers' failure to get aquaculture inputs like feed. It also accounted for the inability of potential adopters and farmers who have abandoned cage aquaculture to start or continue cage aquaculture respectively. Major opportunities identified include; availability of the market for the fish, willingness of the financial institutions to offer loans at a cheaper interest rate, availability of the extension services at the sub-county level. Our preliminary recommendations is that the government can also provide subsidies to most expensive inputs like feeds, seine-net, water testing kits and construction costs for aquaculture. There is need to empower and build capacity for the extension workers through improved good management practices like feed and feeding and record keeping.
\end{abstract}

Keywords: Tilapia, Cage Aquaculture, Adoption Constraints, Finance, Extension, SWHAEZ

\section{Introduction}

Fish and fisheries products have increasingly remained one of the major foreign exchange earners in Uganda with the sector contributing to total export earnings of $4.9 \%$ [1]. The sector employs nearly 500,000 people directly involved in fishing and fish processing. Overall, 1.2 million people depend on the sector for household income [2]. However, this resource is susceptible to depletion due to over-exploitation. Fish farming and management of the fisheries resources can ensure sustainability in the utilization of the fishery resources. SWHAEZ is blessed with an abundance of scattered inland water mass comprising of minor lakes, streams and rivers which lie in the districts of Kisoro, Kanungu, Rukungiri and the greater Kabale [3]. These water bodies have the potential to serve in a versatile capacity for fish production. South Western Highland Agro-Ecological Zone's domestic fish production is dominated by the smallscale artisanal farmers who could be encouraged to go into cage fish farming system utilizing the vast available scattered inland water bodies. The available water bodies (Bunyonyi (in Kabale), Mutanda, Mulehe, Chahafi, Kayumbu (Kisoro), Kimbugwe and Garubunda (in Rukungiri) could offer opportunities for fish farming in the Southwestern highland Agro-ecological zone of Uganda. However, the potential of these natural water bodies for capture fisheries is not documented.

Besides capture fisheries, aquaculture has been in existence in the zone for the last 6 decades [4]. Despite this long history, a rich aquatic resource and high desire for aquaculture in the zone, the enterprise is still at a subsistence scale [5]. Therefore, the project aimed at making informed 
decisions on existing natural water bodies, fish introductions and on the management practices that can boost the productivity of fish in the SWHAEZ.

Aquaculture in SWHAEZ has been predominantly landbased since its inception in the 1950's. There are currently about 350 ponds operated by more than 300 fish farmers in districts of Kanungu, Kisoro, Rukungiri and greater Kabale [6]. Despite these numbers the contribution of aquaculture to local fish production is still insignificant. Available data suggests that the output from aquaculture in 2014 was estimated to be less than $1 \%$ of local fish production [7]. Increasing aquaculture production will be a major step towards food security in SWHAEZ and a further step in achieving $20 \%$ of local production, similar to the global mean, which the government seeks [8]. In order to achieve this goal in addition to meeting the estimated annual deficit of 400, $000 \mathrm{mt}$ (9) and cage aquaculture must be given serious consideration since land-based aquaculture in SWHAEZ is mostly extensive and the land is finite [10].

SWHAEZ is blessed with an abundance of scattered inland water mass comprising of minor lakes, streams and rivers which lie in the districts of Kisoro, Kanungu, Rukungiri and the greater Kabale. These water bodies have the potential to serve in a versatile capacity for fish production. South Western Highland Agro-Ecological Zone's domestic fish production is dominated by the small-scale artisanal farmers who could be encouraged to go into cage fish farming system utilizing the vast available scattered inland water bodies [11]. The available water bodies (Bunyonyi (in Kabale), Mutanda, Mulehe, Chahafi, Kayumbu (in Kisoro), Kimbugwe and Garubunda (in Rukungiri) could offer opportunities for fish farming in the Southwestern highland Agro-ecological zone of Uganda. Utilizing only $1 \%$ of the area of natural water body (approximately $8502 \mathrm{~km}^{2}$ ) [12] corresponds to about 8500 hectares of water. This quantity of water is more than 10 times the area used for land-based aquaculture, about 468 hectares, estimated with 1,300 farms with mean size of 0.36 hectares [13]. The culture of other desirable species such as the catfishes can also be expanded through cage aquaculture in addition to Nile tilapia (Oreochromis niloticus) which is currently the only species cultured in cages in SWHAEZ [14]. There is no doubt that cage aquaculture has the potential to make significant contribution to total fish production and food security in SWHAEZ. Uganda is a good example of a country where cage aquaculture has played an important role in inland fish yields mostly in the central parts [15]. During 1978 to1993, production from cage aquaculture accounted for $67.5 \%$ of total fish production of inland water bodies [16]. It has been suggested that if cage farmers in SWHAEZ can produce yields of $50-150 \mathrm{~kg} / \mathrm{m}^{3} / 9$ months as done elsewhere in Africa, less than 100 hectares of fish cages can produce yields matching the current capture fisheries production of $90,000 \mathrm{mt}(17)$.

Evidently cage aquaculture is not without negative environmental impacts. However, most impacts can be avoided if appropriate policies are implemented to limit the area of water allocated for cage aquaculture, which is currently being considered. Having significant national water resources for cage aquaculture is an important first step, but national development policy for cage aquaculture should be cognizant of other complex and interacting constraints to cage aquaculture development as have already been documented elsewhere (18). Cage aquaculture has been developing in Uganda consistently in the last decade but there have been no significant contribution in the overall aquaculture production figures. Major constraints to aquaculture development suggested for Sub-Saharan Africa are feed and seed quality and availability, cost of cage design and construction, and financing (18). Other constraints identified include lack of technical know-how [16, 18], lack of market [18], lack of processing, lack of access to information and support [17], conflict over water use among others.

Many of the constraints suggested have been attributed to aquaculture in general and are likely to be constraints facing cage farmers but because they are mostly described for the entire sub-Saharan Africa, it becomes difficult to develop policy strategies and solutions targeting specific constraints. It is imperative that each country identifies its specific set of constraints and prioritize development interventions accordingly.

The study aimed at identifying the constraints and potential opportunities of the aquaculture industry to local fish production in SWHAEZ. From the policy perspective, this study informs the different fisheries and aquaculture stakeholders about the most feasible interventions necessary for expanding cage aquaculture.

Specific objectives

To identify major challenges facing cage fish farming in SWHAEZ.

To identify any opportunities that could be exploited to increase the contribution of cage aquaculture to fish production in SWHAEZ.

\section{Methods}

\subsection{Description of the Study Area}

The study was conducted in communities around the different minor lakes of SWHAEZ where there are present or past cage aquaculture activities. The minor lakes are currently the main inland water bodies used for cage fish farming in SWHAEZ. They present enormous opportunities for aquaculture expansion. Communities around these lakes are mainly engaged in fishing and farming employing mostly men with the women focusing on fish processing and trading. These minor lakes are found in the districts of Kabale, Rubanda and Kisooro with $90 \%$ of the lakes located in Kisoro district. Lakes, Kayumbu, Mulehe, Mutanda (in Kisoro) and Lake Bunyonyi in Kabale were the main focus of this study. The respondent groups from the districts in the zone were identified and selected based on the recommendations from the fisheries officers. 


\subsection{Sample Selection and Data Collection}

The surveys were done with three main respondents including current cage fish farmers, cage fish farmers who have abandoned the business and potential adopters represented by people with fish-related livelihoods such as pond aquaculture and trading in fish. The other respondents were the aquaculture technicians, district fisheries officers and representatives of financial institutions. The group consisted of people already employed in fishing activities including fishermen, pond based fish farmers and fish traders. District Fisheries Officers function as extension officers to fish farmers in addition to their prescribed duties. Therefore we included this respondent group to learn about their perspectives of what the constraints in cage aquaculture in the zone were.

With the exception of potential adopters and financial institutions, all respondents identified for this study had small populations which were easily accessed through census. A list of Adopters and Abandoned was obtained from the Fisheries Officers and contacted as many as were available. Where we could not contact farmers directly, we employed opinion leaders to help access them. The study also conducted interviews with selected financial institutions based on their availability and preparedness to voluntarily answer questions.

The field studies were conducted between February and May 2017. Surveys and interviews were employed in this study. Questionnaires were administered in person to ensure answers provided were directed to exact questions asked. A total of 82 questionnaires were administered. Questionnaires were structured to suit respondent groups but we incorporated similar questions in some questionnaires to aid comparison among groups. In this study, 23 Adopters, 19 Abandoned and 29 Potential Adopters were interviewed. The study also identified and administered 1 questionnaire to the Fisheries and aquaculture technician for the Zonal research institute, 5 questionnaires to the district Fisheries Officers, and 5 financial institutions. Key informants in relevant government institutions were further interviewed.

\subsection{Questionnaire Design}

Based on the information available in the literature about constraints in aquaculture in general and cage aquaculture in specific, nine items representing constraints that could be evaluated by Adopters, Abandoned and Potential Adopters were developed. The nine items were presented and scored on a four-point interval scale ranging from "not important" to "very important" modified from level of problem type-scale. Respondents were to rank the constraints according to how important they were in their cage aquaculture operations, their decision to abandon or adopt the business. Additionally we presented the same set of constraints to the fisheries and aquaculture technician and the district fisheries officers. An open-ended option was provided for respondents to state other constraints that thought were very important.

Adopters, Abandoned and Potential Adopters were asked to indicate (yes/no) whether they had had specific cage aquaculture training. An open ended question of the type of training, where and when they had the training was followed. Multiple measures of training as a way of assessing the level of knowledge of respondents in cage aquaculture were used.

The market availability for products, the profitability of cage aquaculture from the respondents' perspective, and interest in the business were also evaluated. To do this, a series of binary response questions which were presented to the appropriate respondent groups was developed. Adopters were asked to indicate (yes/no) whether they thought they would be able to sell more fish if they could expand production above their current level. Then they were asked them if they would recommend cage aquaculture to potential farmers. Potential Adopters were asked to indicate (yes/no) whether they were interested in starting cage aquaculture in the minor lakes of the zone. Both Abandoned and Potential Adopters were asked to indicate (yes/no) if they were interested in resuming or starting cage aquaculture if constraints are removed, and to provide reasons for their responses.

Opportunities available for farmers to access loans from banks and financial institutions were explored through both close-ended and open-ended questions. Financial institutions were asked to indicate (yes/no) if they had given loans to fish farmers in the past. When the response was yes, they were further asked to indicate the percentages of farmers who paid the loan at the appointed time, sometime after the appointed time or never repaid the loan. Future opportunities for loans were explored by asking financial institutions to indicate (yes/no) whether they had some form of budget for fish farmers currently. For those that responded in the affirmative, we asked them to provide specific requirements that farmers needed to meet in order to access a loan.

\subsection{Interviews}

Select questions were used from the questionnaires as an interview guide in conducting the interviews with the key informants in government research institutions. Interviewees were asked their opinions about the constraints in cage aquaculture in the zone and opportunities they knew existed which could improve the industry. Notes were taken in all interviews but recorded none of the interviews to avoid making interviewees uncomfortable.

In this preliminary analysis, the quantitative questions in the surveys were analyzed using descriptive statistics such as arithmetic means, percentages and proportions and the qualitative questions were either coded and analyzed using descriptive statistics or analyzed qualitatively. All interviews were transcribed and stored to await analysis with the surveys.

\section{Results and Discussion}

\subsection{Constraints in Cage Fish Farming}

Overall, the three main respondents groups (Adopters, Abandoned and Potential Adopters), the Fisheries and 
aquaculture technicians and district fisheries officers ranked lack of funds high on a 4-point scale. Mean ranking of lack of funds was 3.58 for Adopters (Figure 1). Abandoned and Potential Adopters had mean rankings of 3.25 and 3.81 respectively. Due to the small sample size of the district fisheries officers ( $n=1$ and 5 respectively), their means were not included in the comparisons but it is worth mentioning that the Fisheries and aquaculture technician ranked lack of funds as very important (4) whiles the district officers had a mean ranking of 4 for the same constraint.

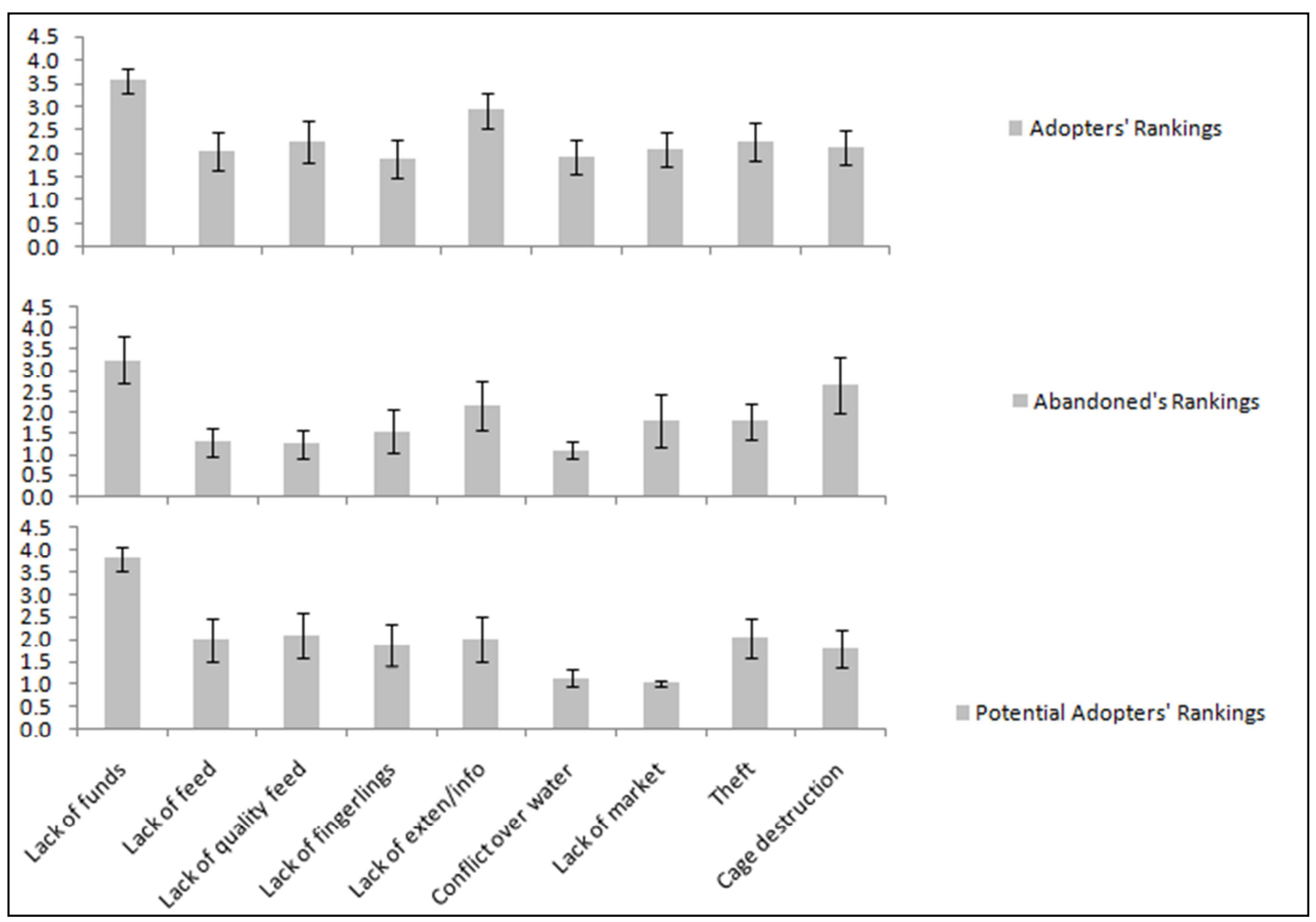

Figure 1. Ranking of the different constraints at 95\% confidence intervals Error bars.

The results from the survey suggest that lack of funds is the main constraint in cage aquaculture and not lack of feed and fingerlings as has been suggested for Sub-Saharan Africa. This is in agreement with findings by Asiedu et al. (2017) in Sunyani Fisheries Zone of Ghana. Their study observed that lack of access to funds is among the multiple factors for high cost of production and farm abandonment. Additionally, lack of good fingerlings is also ranked among the most factors affecting cage aquaculture in the Zone though Kachwekano Zonal Agricultural Research and Development Institute has conducted extensive research to improve the genetic quality of tilapia brood-stock and fingerlings in the zone. When the respondents were asked to state other constraints they thought were important, high feed cost emerged as the most important constraint. More so, extra information provided by some respondents in the focus group discussions indicated that high feed cost and accessibility was an important constraint (Figure 2). This result validates the opinion of [18] who said the availability of high-quality locally produced feeds at competitive prices in sub-Saharan Africa was a constraint in cage aquaculture. High feed costs also translated into high fish price, which some farmers felt affected their profit (Figure 3) even though lack of market was not necessarily a major constraint according to the survey results.

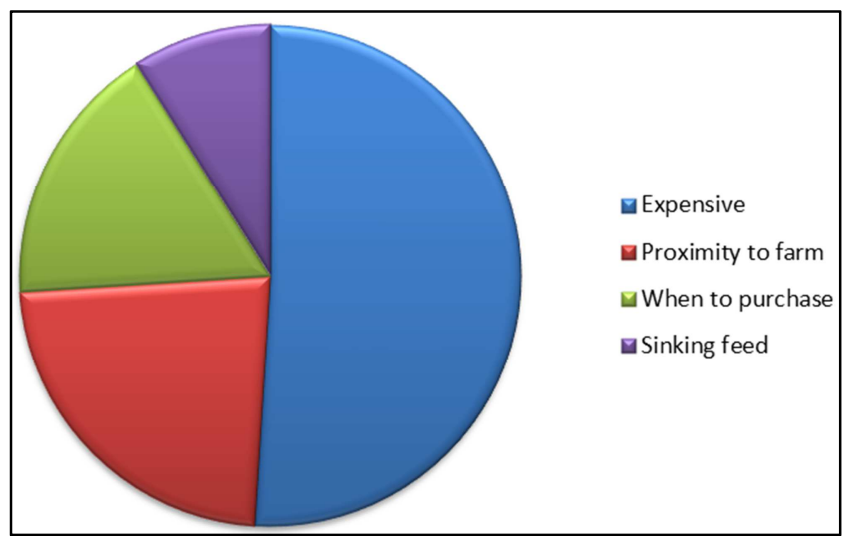

Figure 2. Respondents who provided additional information about other factors they considered constraints in relation to lack of feed and good quality feed. 


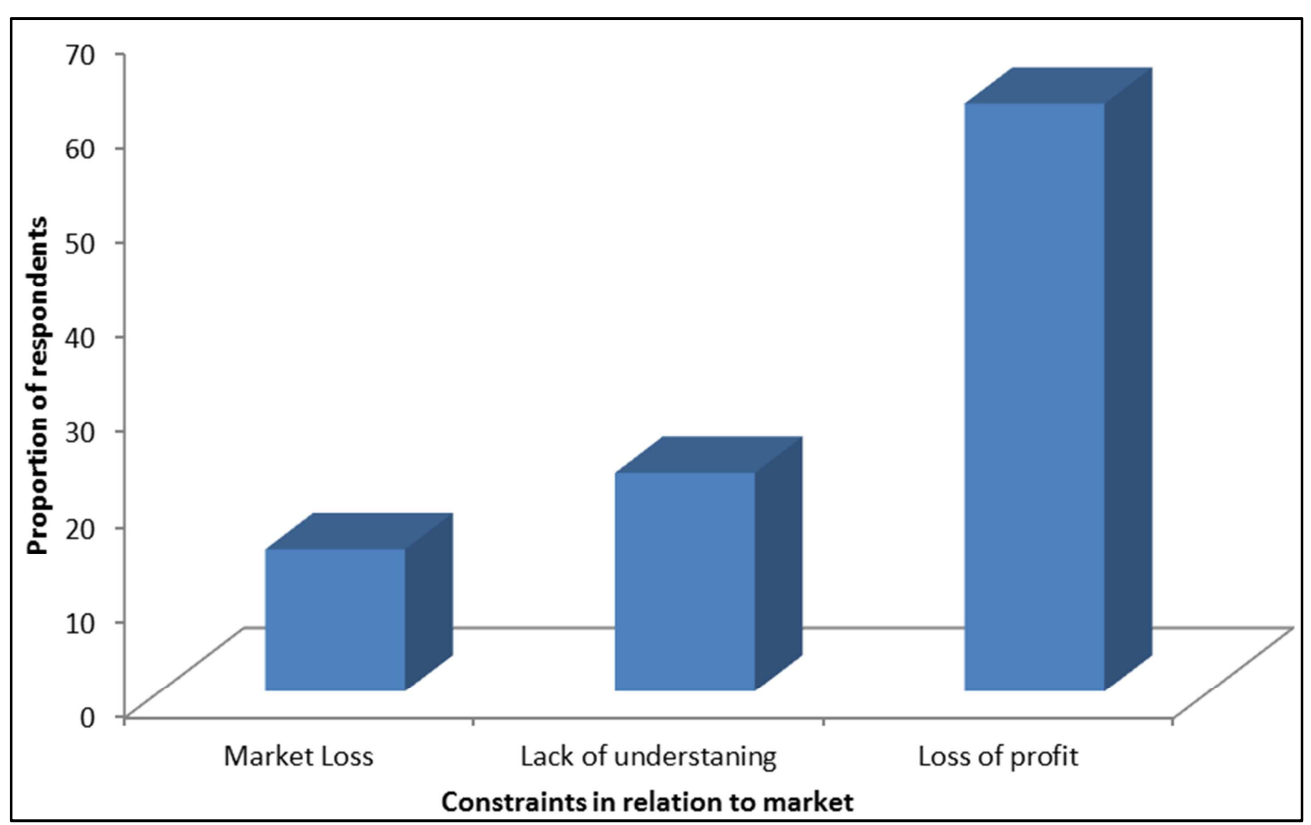

Figure 3. Respondents with additional information about other factors they considered constraints in relation to lack of market.

Lack of funds could explain why they are not currently practicing cage aquaculture mostly to the potential adopters. When asked if they adopters were interested in resuming the business, all the respondents in the abandoned group showed interest in resuming cage aquaculture if they had capital.

Lack of extension was ranked as the second most important constraint by cage fish farmers with a mean of 2.93 (Figure 1). Again, lack of extension was ranked as very important (4) by fisheries and aquaculture technician. However, both the Abandoned and Potential Adopters rated lack of extension or lack of information (for Potential Adopters) as a slightly unimportant constraint. In contrast, the district fisheries officers ranked lack of extension quiet low with a mean of 1.6. This is probably because the district fisheries officers felt they were doing their best doubling as extension officers in addition to their assigned duties.

Apart from lack of funds and lack of extension, respondents ranked quality feeds as the third constraint in cage fish farming (mean rank of 2.3 or lower). The major barrier to competitive cage culture development is lack of availability of domestically made quality extruded fish feeds at competitive prices [19]. The only exceptions were theft which was 3.4 by the Fisheries officers and farmers. Theft was probably ranked high by the Fisheries and aquaculture technician and the district fisheries officers because of individual reports by some farmers but it appears that once funds are available to hire security personnel on farms, the problem of theft is easily dealt with.

Interview results shared some similarities with survey result in terms of lack of extension being a major constraint in cage fish farming. Whereas all three interviewees mentioned lack of extension specifically, only one mentioned lack of funds as a constraint. Interestingly, all three interviewees stated lack of knowledge in cage aquaculture as the main constraint. However, this was not evident in the survey because when asked if they had specific training in cage aquaculture, we had yes response of $72 \%, 85 \%$ and $55 \%$ for Adopters, Abandoned and Potential Adopters respectively.

\subsection{Different Opportunities to Be Exploited in the Sector}

Most farmers responded yes in line with marketing their produce suggesting a great potential for boosting their incomes and more export earnings from fish for the country since fish sector enjoys fortunes from favorable international fish market prices.

Farmers also recommended cage fish farming as a venture that is likely to enhance famers' profitability due to high market demand both at regional and national level

Farmers are also willing to start up cage fish farming because of its minimal costs in operation and setting up. Results from the survey also showed that some government agencies had trained farmers in the cage fish farming and this is likely to increase the production of the fish in SWHAEZ.

\section{Conclusions and Recommendations}

The survey suggests that lack of funds to purchase input such as feed, fingerlings is the main constraint in cage aquaculture in the zone. Lack of money prevented farmers who had abandoned and at the same-time farmers who had interests in starting up fish farmers. Farmers also had limited knowledge in management and operation of the cages to raise fish thus need for extension services.

Aquaculture through cage fish farming has the potential to increase fish production especially in the current state of low capture fisheries. Boosting aquaculture could be through subsidizing feed cost for small-holders, especially if quality floating feed is produced locally. The government can also provide subsidies to most expensive inputs like feeds, seinenet, water testing kits and construction costs for aquaculture. 
There is need to empower and build capacity for the extension workers through improved good management practices like feed and feeding and record keeping

\section{Acknowledgements}

This study was funded by ATAAS-World Bank in collaboration with the National Agricultural Research Organization. We are so grateful to the different enumerators who supported in administering the questionnaires.

\section{References}

[1] Uganda Bureau of Statistics [UBOS]. (2017). 2017 Statistical Abstract. Kampala, Uganda.

[2] Kwikiriza G, Barekye A, Aheisibwe AR, Byakora E and Tibihika PD, (2017). Comparative Growth Performance and Proximate Nutrient Composition of Three Local Strains of Nile Tilapia (Oreochromis Niloticus L.) Collected From Different Locations in Uganda. Fisheries and Aquaculture Journal, 8(3):226-23.

[3] Balarin J. D. (1985) National reviews for aquaculture development in Africa: Tanzania. FAO Fisheries Circulars No. (770.11). FAO, Rome, Italy (KAZARDI, 2012).

[4] Papius, D. M. Tibihika (2014). Fish farming dynamics in South Western Highlands Agro-Ecological Zone, SWHAEZ, baseline survey in Kabale, Kisoro, Rukungiri and Kanungu Districts International Journal of Fisheries and Aquatic Studies; 1(5): 182-205.

[5] Abban, E. K., J. Moehl, L. K. Awity, M. Kalende, J. K. Ofori, and A. Tetebo. (2006). Aquaculture Strategic Framework. Ministry of Fisheries. 33p.

[6] Asmah, R. (2008). Development potential and financial viability of fish farming in Ghana. PhD Thesis. University of Stirling, Stirling, UK.

[7] Kwikiriza G, Barekye A Muhereze R, Tibihika P. D. M, (2016), Growth performance of Monosex Nile Tilapia (Oreochromis niloticus) juveniles at different stocking densities in cages at Lake Bunyonyi in South Western Highland Agro-Ecological Zones (SWHAEZs), International Journal of Fisheries and Aquatic Studies 4(6): 42-48.

[8] International Lake Environment Committee Foundation (1999). World Lake Database. Accessed: March 26, 2010 at http://www.ilec.or.jp/database/afr/afr-16.html.

[9] Kwikiriza G, Namulawa V, Wadunde O. A, Abaho I, Constantine Chobet Ondhoro C. C, (2016), Proximate nutrient composition and cost of the selected potential fish feed ingredients in Lake Victoria basin, Uganda, International Journal of Fisheries and Aquatic Studies, 4(3): 611-615.

[10] Baotong, H., and Y. Lui. (1998). The development of cage culture and its role in fishery enhancement in China. In T. Petr (ed). Inland fishery enhancement. Papers presented at the FAO/DFID expert consultation on inland fishery enhancement. Dhaka, Bangladesh, 7-11 April. FAO Fisheries Technical Paper. No. 374. Rome. 463p.

[11] Ofori, J. K., E. K. Abban, A. Y. KariKari, and R. E. Brummett. (2010). Production parameters and economics of small-scale tilapia cage aquaculture in the Volta Lake, Ghana. Journal of Applied Aquaculture. 22:337-351.

[12] Hambrey, J. (2006). Cage culture - the challenges. Page 73 in M. Halwart, and J. F., Moehl (eds). FAO Regional Technical Expert Workshop on cage culture in Africa. Entebbe, Uganda, 20-23 October 2004. FAO Fisheries Proceedings. No. 6. Rome.

[13] Hishamunda, N. and P. Manning. (2002). Promotion of sustainable commercial aquaculture in sub-Saharan Africa: Investment and economic feasibility. FAO Fisheries Technical Paper. No. 408/2. Rome. 54p.

[14] Halwart, M., and J. F., Moehl (eds). (2006). FAO Regional Technical Expert Workshop on cage culture in Africa. Entebbe, Uganda, 20-23 October 2004. FAO Fisheries Proceedings. No. 6. Rome. 113p.

[15] Moehl, J., R. Brummet, M. K. Boniface, and A. Coche. (2006). Guiding principles for promoting Aquaculture in Africa: benchmarks for sustainable development. CIFA Occasional Paper No. 28, Accra. 122p.

[16] Blow, P. and S. (Leonard. 2007). A review of cage aquaculture: sub-Saharan Africa. Pages 188-207 in M. Halwart, D. Soto and J. R. Arthur, editors. Cage aquaculture Regional reviews and global overview, FAO Fisheries Technical Paper. No. 498. Rome, 241p.

[17] Ridler, N. and N. Hishamunda. (2001). Promotion of sustainable commercial aquaculture in sub-Saharan Africa: Policy framework. FAO Fisheries Technical Paper. No. 408/1. Rome. 67p.

[18] Vagias, W. M. (2006). Likert-type scale response anchors. Clemson International Institute for Tourism \& Research Development, Department of Parks, Recreation and Tourism Management. Clemson University. 1p.

[19] Munguti, J. M., Kim, J., and Ogello, E. O. (2014). An overview of Kenyan aquaculture: Current status, challenges, and opportunities for future development.. Fisheries and aquatic sciences, 17, 1-11. 